\title{
Juvenile Acanthosis Nigricans and Insulin Resistance
}

\author{
Trinh Hermanns-Lê, M.D., Jean François Hermanns, M.D., and Gérald E. Piérard, M.D., Ph.D. \\ Department of Dermatopathology, University Medical Center of Liège, Liège, Belgium
}

\begin{abstract}
Acanthosis nigricans in obese adolescents is frequently associated with hyperinsulinemia and insulin resistance. We report three cases of this condition. In the early stage the skin lesions appeared to be erythematous and pruritic, mimicking an inflammatory dermatitis. Dietary control and oral metformin hydrochloride markedly improved the lesions. Topical calcipotriol may also help to control the skin condition.
\end{abstract}

Normal skin shows remarkable structural and functional diversity depending on anatomic location and environmental influences. Homeostasis of the cutaneous tissues requires the recognition and integration of appropriate signals with a high degree of specificity. The most important mechanisms involve the skin immune system, the pigmentary system, and the cutaneous neuroendocrine system. In particular, many cell types in the skin possess specific hormone receptors and/or produce various hormones (1). As a consequence, many endocrine disorders manifest themselves at the level of the skin.

Acanthosis nigricans is characterized by hyperpigmented skin thickening with hyperplasia of the epidermis and papillary dermis. Lesions develop on any part of the body, but involve particularly the axillae, the nape and sides of the neck, and the groin. Recent attention has been focused toward its benign presentation associated with hyperinsulinemia and insulin resistance (2-4). We report three cases of juvenile acanthosis nigricans associated with obesity and insulin resistance.

\section{CASE REPORTS \\ Patient 1}

A 16-year-old Moroccan girl presented with hyperpigmented velvety to papillomatous plaques on the posterior cervical region (Fig. 1) and in other cutaneous folds (Fig. 2). These lesions had been present for about 3 years. A biopsy specimen from the nape of the neck showed papillomatosis, acanthosis, and hyperkeratosis consistent with the diagnosis of acanthosis nigricans (Fig. 3). Topical applications of calcipotriol improved the lesions. She also had erythematosquamous, slightly hyperpigmented and pruriginous plaques all over her skin (Fig. 4). A cyanoacrylate skin surface stripping harvested from the trunk revealed the presence of parakeratotic and lymphoid cells. Topical corticotherapy failed to improve the lesions. A skin biopsy specimen from such a lesion on the trunk showed epidermal changes typical of acanthosis nigricans.

The body mass index reached $29.7 \mathrm{~kg} / \mathrm{m}^{2}(77.5 \mathrm{~kg}$ for $161.5 \mathrm{~cm}$ ). Blood examination revealed normoglycemia

Address correspondence to G. Piérard, M.D., Department of Dermatopathology, CHU Sart Tilman, B-4000 Liège, Belgium, fax 32 (0) 43662976 or e-mail: gerald.pierard@ulg.ac.be. 


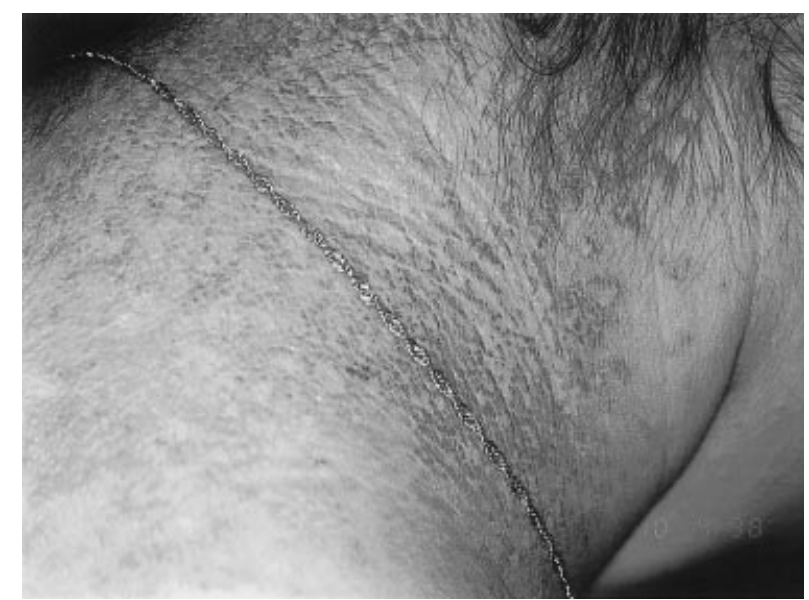

Figure 1. Hyperpigmented and papillomatous plaques in the posterior cervical region (patient 1).

$(1 \mathrm{~g} / \mathrm{L})$ at fasting (normal $0.7-1.1 \mathrm{~g} / \mathrm{L}$ ) and a normal response to a $75 \mathrm{~g}$ oral glucose tolerance test (OGTT). However, the patient showed hyperinsulinemia $(38.3 \mu \mathrm{U} / \mathrm{ml})$ at fasting (normal $2-25 \mu \mathrm{U} / \mathrm{ml}$ ) and also excessive levels of insulin at 60 and 90 minutes after the glucose challenge (Fig. 5).

Treatment with oral acitretin $25 \mathrm{mg} /$ day and dietary control were initiated. Lesions were cleared 3 months later, but they reappeared rapidly after acitretin was stopped and with poor dietary compliance. Oral metformin hydrochloride initiated at a dose of $850 \mathrm{mg}$ once a day was increased to $850 \mathrm{mg}$ twice a day and combined with better dietary control. The skin lesions resolved and showed no relapse during a 1-year treatment.

\section{Patient 2}

A 12-year-old Caucasian boy developed acanthosis nigricans on his axillae, neck, groins, and antecubital and popliteal surfaces. Surgery for bilateral cryptorchi-

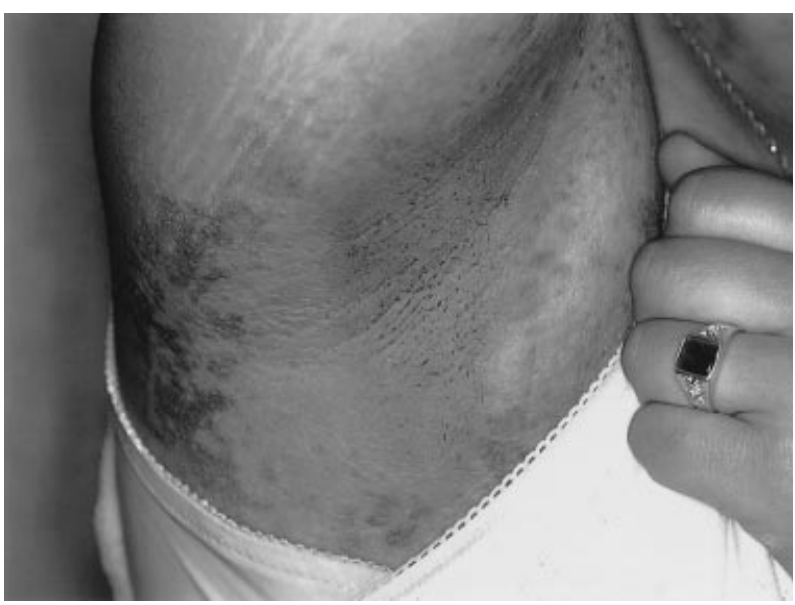

Figure 2. Papillomatous plaques in the axilla (patient 1).

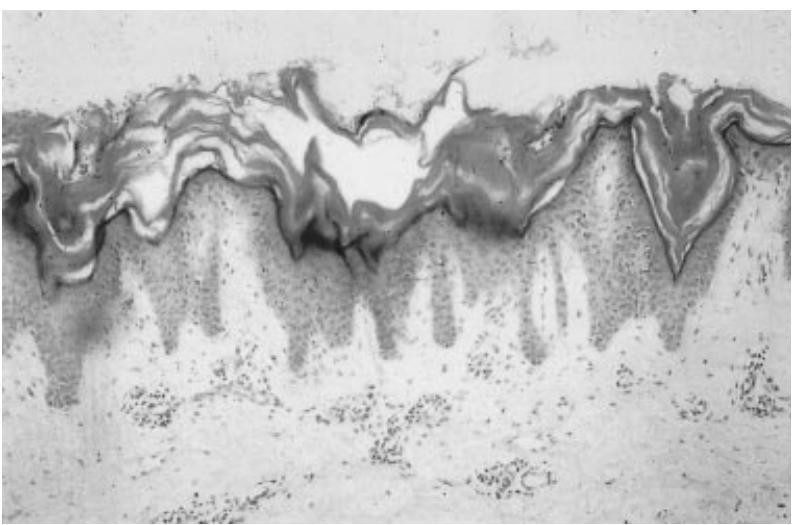

Figure 3. Papillomatosis, acanthosis, and hyperkeratosis typical for acanthosis nigricans (patient 1).

dism had been performed at age 11 years. His body mass index was $31.2 \mathrm{~kg} / \mathrm{m}^{2}(80.8 \mathrm{~kg}$ for $161 \mathrm{~cm})$. Glycemia at fasting $(0.9 \mathrm{~g} / \mathrm{L})$ and after OGTT were normal, but hyperinsulinemia was present at fasting $(31.4 \mu \mathrm{U} / \mathrm{ml})$, and also 60, 90, and 120 minutes after OGTT (Fig. 5). No other endocrine anomaly was disclosed. Treatment with oral metformin hydrochloride $850 \mathrm{mg}$ once a day and dietary control improved the skin lesions.

\section{Patient 3}

A 12-year-old Caucasian girl presented with symmetrical, well-delimited, maculoerythematous plaques on the axillae mimicking psoriasis inversa. Topical corticosteroids failed to improve the lesions. She developed new lesions on the neck and trunk after 2 weeks which suggested acanthosis nigricans. A skin biopsy specimen from the axillary lesion revealed hyperorthokeratosis, papillomatosis, and acanthosis. Her body mass index reached $24.8 \mathrm{~kg} / \mathrm{m}^{2}$ (50 kg for $\left.142 \mathrm{~cm}\right)$. At fasting, glycemia was normal $(0.91 \mathrm{~g} / \mathrm{L})$, but insulin was elevated $(31.2 \mu \mathrm{U} / \mathrm{ml})$. OGTT was not performed. She refused dietary control and oral treatment. She just applied topical calcipotriol, resulting in a modest improvement of the skin condition.

\section{DISCUSSION}

Acanthosis nigricans unrelated to malignancy may be congenital, juvenile in onset, or develop during early adulthood. It is often associated with obesity and may be more frequent in the black population (2). Typical acanthosis nigricans is described as light brown to black verrucous or papillomatous hypertrophic lesions. In two of the present juvenile cases, the initial lesions were erythematous and pruritic, mimicking an inflammatory psoriasiform dermatitis. 


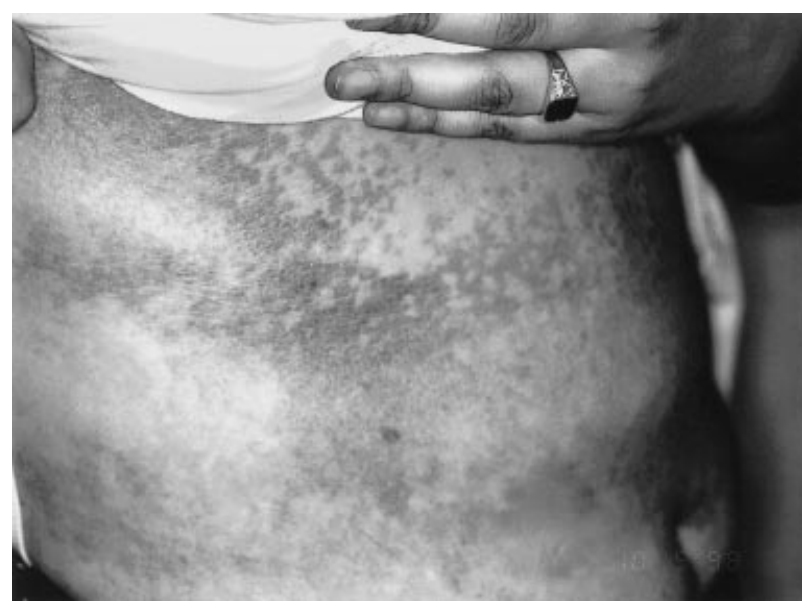

Figure 4. Diffuse erythematosquamous and hyperpigmented lesions on the trunk (patient 1).
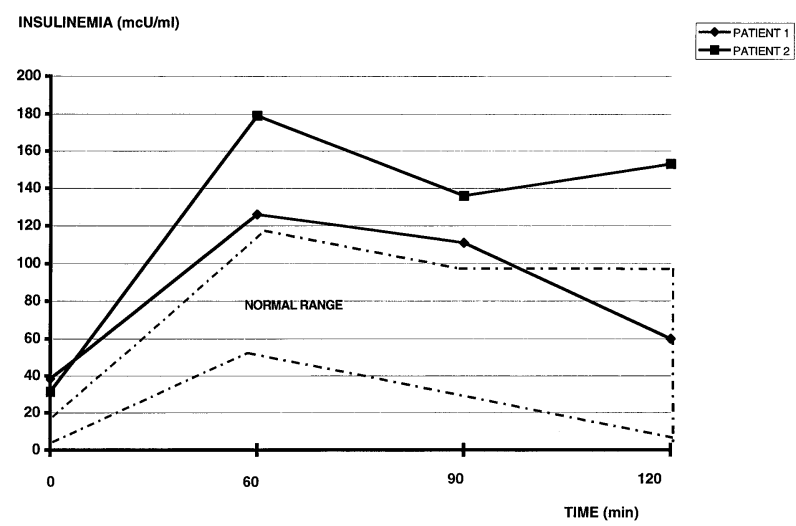

Figure 5. Insulinemia following $75 \mathrm{~g}$ oral glucose intake by two juvenile obese patients (patients 1 and 2) with acanthosis nigricans. Values are in excess of the normal range.

In our three patients, acanthosis nigricans was most likely related to hyperinsulinemia and insulin resistance. This hormone binds to specific cell receptors and serves as a growth factor for keratinocytes and fibroblasts $(2,5-7)$. Three types of insulin resistance are described $(2,7)$ : type A with a reduced number or dysfunction of insulin receptors, type $\mathrm{B}$ caused by antibodies directed to insulin receptors, and type $\mathrm{C}$ with a postreceptor defect. Insulin resistance associated with obesity belongs to the type A group, which is accompanied by elevated plasma levels of testosterone in most patients (2). However, no endocrine disorder other than insulin resistance was disclosed in our patients.
The diagnosis of acanthosis nigricans calls for a careful search for endocrine diseases or internal malignancies. Insulin resistance is frequently found in young obese patients. Oral retinoids may be of some benefit to these patients (8), but their effect is only transient when hyperinsulinemia is not controlled. Hence dietary control is important for treatment success $(2,4)$. We presently highlight the efficacy of metformin hydrochloride. This biguanide drug, usually used in type II diabetes mellitus, increases both the peripheral response to insulin and the cellular glucose metabolism. Furthermore, it inhibits hepatic glucogenesis and decreases the delayed glucose intestinal absorption. In two of our three patients, correcting hyperinsulinemia was presumably accomplished by metformin and led to resolution of their acanthosis nigricans. Weight control alone was not attempted because it was not expected to be easily accomplished and relevant to control the skin condition.

In conclusion, insulin-dependent juvenile acanthosis nigricans associated with obesity is a reversible condition that can be controlled by adequate dietary measures and metformin hydrochloride. Topical calcipotriol can help to improve the cutaneous changes.

\section{REFERENCES}

1. Slominski A, Wortsman J. Neuroendocrinology of the skin. Endocr Rev 2000;21:457-487.

2. Schwartz RA. Acanthosis nigricans. J Am Acad Dermatol 1994;31:1-19.

3. Esperanza LE, Fenske NA. Hyperandrogenism, insulin resistance and acanthosis nigricans (AIR-AN) syndrome: spontaneous remission in a 15 -year-old girl. J Am Acad Dermatol 1996;34:892-897.

4. Kuroki R, Sadamoto Y, Imamura M, et al. Acanthosis nigricans with severe obesity, insulin resistance and hypothyroidism. Improvement by diet control. Dermatology 1999;198:164-166.

5. Moller DE, Flier JS. Insulin resistance-mechanisms, syndromes and implications. N Engl J Med 1991;325: 938-948.

6. Cruz PD Jr, Hud JA Jr. Excess insulin binding to insulin-like growth factor receptors: proposed mechanism for acanthosis nigricans. J Invest Dermatol 1992;98:S82-S85.

7. Humbert PH, Nguyen NU. Physiopathologie de l'acanthosis nigricans. Ann Dermatol Venereol 1998;125:851-855.

8. Akovbyan VA, Talanin NY, Arifov SS, et al. Successful treatment of acanthosis nigricans with etretinate. J Am Acad Dermatol 1994;31:118-120. 